\title{
Diabetes mellitus tanısı olan hastalarda hiperlipidemi ve HbA1c'deki değişimin MPV ve RDW üzerine etkisi
}

\section{Effect of hyperlipidemia and change in HbAlc on MPV and RDW in patients with diabetes mellitus}

\author{
๑Selma Karaahmetoğlu1, ๑Rukiye Kara ${ }^{2}$, ๑Adil Uğur Çetin², ĐEce Ünal Çetin ${ }^{2}$ \\ ${ }^{1}$ Ankara Numune Eğitim Araştırma Hastanesi, Ankara, Türkiye \\ ${ }^{2}$ Kütahya Emet Dr. Fazıl Doğan Devlet Hastanesi, Kütahya, Türkiye
}

Cite this article as/Bu makaleye atıf için: Karaahmetoğlu S, Kara R, Çetin AU, Ünal Çetin E. Diabetes mellitus tanısı olan hastalarda hiperlipidemi ve HbAlc'deki değişimin MPV ve RDW üzerine etkisi. J Med Palliat Care 2021; 2(3): 86-90.

\begin{abstract}
ÖZ
Amaç: Diabetes mellitus (DM) subklinik, sistemik, düşük dereceli inflamatuvar bir endotel hastalığı olarak kabul görmektedir. Ortalama trombosit hacmi (MPV) ve eritrosit dağılım aralığı (RDW) birçok çalışmada inflamasyon ile ilişkisi araştırılmış olan hematolojik parametrelerdir. Çalışmamızda amacımız DM tanılı hastalarda HbAlc ve lipid profili ile hematolojik parametrelerden MPV ve RDW ilişkisini incelemek olmuştur.

Gereç ve Yöntem: Retrospektif olarak planlanan çalışmaya tip 2 DM tanılı 100 hasta alındı. Diyabet tanı tarihleri, kan şekeri regülasyonu için aldıkları tedavi, diyabet ilişkili mikro ve makrovasküler komplikasyonları, HbAlc’nin yüksek olduğu dönemde ve tedavi sonrasında HbAlc’nin düștügü dönemde açlık ve tokluk kan glukozu, lipid profili, hematolojik parametreleri retrospektif olarak incelendi.

Bulgular: Çalışmaya 58 kadın ve 42 erkek hasta dahil edildi. Ortalama DM tanı süresi 3 yıl 3 ay olarak bulundu. Hastaların ilk başvuru anındaki ortalama HbAlc \%9,4 iken aynı hasta grubunun kontrol muayenesi başvurusunda ortalama HbA1c \%7,4 olarak saptandı. Her iki grup karşılaştırıldığında RDW (p:0,009) için anlamlı farklılık tespit edilmesine rağmen MPV (p:0,902) için anlamlı farklılık tespit edilmemiştir. Sonuç: Bu çalışmada HbA1c değerindeki düşüş sonrası RDW değerinde artış olduğu sonucuna varılmıştır. MPV için DM tanılı hastalarda istatistiksel anlamlılık saptanmamıştır. HbAlc değerine alternatif olarak RDW değerinin de takipte kullanılabileceği, MPV için daha fazla hasta sayısı ile çok merkezli çalışmalara ihtiyaç olduğu düşünülmektedir.
\end{abstract}

Anahtar Kelimeler: Diabetes mellitus, MPV, RDW, hiperlipidemi

\begin{abstract}
Aim: Diabetes mellitus (DM) is accepted as a subclinical, systemic, low-grade inflammatory endothelial disease. Mean platelet volume (MPV) and erythrocyte distribution range (RDW) are hematological parameters whose relationship with inflammation has been investigated in many studies. In our study, our aim was to examine the relationship between HbAlc and lipid profile and hematological parameters, MPV and RDW, in patients with DM.

Material and Method: 100 patients with type 2 DM were included in the study, which was planned retrospectively. Diabetes diagnosis dates, treatment for blood sugar regulation, diabetes-related micro and macrovascular complications, fasting and postprandial blood glucose, lipid profile, hematological parameters during the period when HbAlc was high and after treatment when HbAlc decreased were analyzed retrospectively.

Results: 58 female and 42 male patients were included in the study. The mean duration of DM diagnosis was 3 years and 3 months. While the mean $\mathrm{HbAlc}$ at the time of first admission was $9.4 \%$, the mean $\mathrm{HbAlc}$ was found to be $7.4 \%$ in the control examination application of the same patient group. When the two groups were compared, although a significant difference was found for RDW (p:0.009), no significant difference was found for MPV (p:0.902).

Conclusion:In this study, it was concluded that there was an increase in RDW value after the decrease in HbA1c value. No statistical significance was found for MPV in patients with DM. It is thought that RDW value can also be used in follow-up as an alternative to HbAlc value, and multicenter studies with larger number of patients are needed for MPV.
\end{abstract}

Keywords: Diabetes mellitus, MPV, RDW, hyperlipidemia 


\section{GíRiş}

Tip 2 Diabetes mellitus (DM), sıklıkla obezite ve fiziksel inaktiviteye bağlı olarak gözlemlenen, temel olarak genetik yatkınlığı olan kişilerde yaşam tarzı ile tetiklenen ve giderek artan insülin direnci ve zamanla azalan insülin salınımının söz konusu olduğu kronik metabolik bir hastalıktır. Dünya nüfusunun yaklaşık \%5-10'u tip 2 DM hastasıdır. 2013 yılında yayımlanan Uluslararası Diyabet Federasyonu (IDF) Diyabet Atlası'na göre ülkemiz Avrupa ülkeleri arasında diyabet prevalansının en yüksek olduğu ülkedir (1). Ülkemizde DM \%13,7 prevalansı ile sıklığı giderek artan önemli bir hastalıktır (2). DM metabolik olduğu kadar vasküler bir hastalıktır (3-4). Tip 2 DM kaynaklı başlıca ölüm nedeni kardiyovasküler komplikasyonlardır (5). Bazı çalışmalarda koroner arter hastalığının diyabetiklerdeki sıklığının genel topluma göre 6 kata kadar arttığı bulunmuștur ve bu nedenle Adult Treatment Panel 3 (ATP 3: Erișkin Tedavi Paneli), diyabetin riskini ateroskleroza eș olarak değerlendirmektedir (6).

Son yıllarda yapılan çalıșmalarda inflamasyon ve insülin direnci arasındaki ilişkiye yapılan vurgu dikkati çekmektedir (7-8). DM kronik, subklinik, sistemik, düşük dereceli inflamatuvar bir endotel hastalığ 1 olarak da kabul edilebilir (9). Ancak insülin direncinin bu etkisi, sadece endotel disfonksiyonu yaratarak değil, aynı zamanda kanın şekilli hücreleri ile ilișkiye girerek meydana gelen hematolojik değișiklikler ile de ilgili olabilir. Plateletler aterotrombozun merkezi unsurları olup, en önemli patogenetik özellikleri hasarlı endotelde lökositler ile olan ilişkileridir. Büyük hacimli plateletler daha reaktif kan elemanları olup, inflamatuvar olaylarda daha fazla rol alırlar. MPV, böylelikle DM teşhisinde, vasküler komplikasyonların ağırlığının belirlenmesinde ve tedaviye yanıtın değerlendirilmesinde faydalı olabilecek, ucuz ve pratik bir parametre olarak değerlendirilebilir.

RDW'nin koroner arter hastalığı olan ve kalp yetmezliği tanısı olan hastalarda bağımsız risk faktörü olduğuna ilişkin çalışmalar vardır. Kardiyak hastalıklarda olası mekanizmalar düşünüldüğünde RDW'nin patogenezde sorumlu başka belirteçlerle, örneğin inflamatuvar sitokinler ile ilişkili olabileceği belirtilmektedir. DM kronik, subklinik, sistemik, düşük dereceli inflamatuvar bir endotel hastalığı olarak kabul edilebilir (9). Ayrıca proinflamatuvar sitokinlerin eritropoetin aracilı eritrosit maturasyonunu inhibe etmesiyle RDW değerlerinde de yükselme görülmektedir (10). Yani aslında yüksek RDW değerlerinin altta yatan nedeni şiddetli inflamasyonun ortaya çıkardığı kırmızı kürelerin olgunlaşmasında defekt (ineffektif eritropoez) olabilir (11).

ile diyabetin takip ve tedavisinde lipid anormallikleri agresif olarak araştırılmalı ve tedavi edilmelidir (12).
Bizim çalışmamızdaki amacımız, aterosklerotik belirleyici parametre olan MPV ve RDW ile aterosklerotik neden olarak çok iyi bilinen DM regülasyon parametresi glikolize $\mathrm{Hb}$ değerinin (HbAlc) ve lipid parametrelerinin arasındaki ilişkiyi araştırmaktır.

\section{GEREÇ VE YÖNTEM}

Çalışmaya, 2010-2014 yılları arasında Ankara Numune Hastanesi Dahiliye 2 Polikliniğinde takipte olan tip 2 DM tanılı 100 hasta alındı. Çalışma retrospektif olarak planlandı. Hastaların verilerine hastane bilgi sisteminden ulaşıldı. Çalışmamız, Ankara Numune Eğitim ve Araştırma Hastanesi Bilimsel Araştırmalar Değerlendirme Komisyonu (Etik Kurulu) tarafından onaylanmıştır (Tarih: 04/06/2014, Karar No: 2014-835).

Tip 2 DM tanısı ile kan şekeri regülasyonu için tedavi alan 18 yaş üstü, anemi, enfeksiyon tablosu, böbrek fonksiyon bozukluğu olamayan hastalar rastlantısal olarak alındı. Ankara Numune Eğitim ve Araştırma Hastanesi bilgi sisteminden; diyabet tanı tarihleri, kan şekeri regülasyonu için aldıkları tedavi, HbA1c'nin yüksek olduğu dönemde ve tedavi sonrasında $\mathrm{HbA}$ lc’nin düştüğü dönem de; açlık kan glukozu, tokluk kan glukozu, total kolesterol, LDL kolesterol, HDL kolesterol, trigliserid, WBC, hemoglobin, trombosit, MPV (mean platelet volume - ortalama trombosit hacmi), RDW (redcell distribution width - kırmızı küre dağılım genişliği) düzeyleri retrospektif olarak incelendi. Anemi için; Hb değeri, enfeksiyon için; CRP, sedimentasyon, WBC yüksekliği, nefropati için; Modification of Diet in Renal Disease (MDRD) formülü kullanılarak hesaplanlanan glomerüler filtrasyon hızı (glomerular filtration rate=GFR) bakıldı. Anemi, enfeksiyon tablosu ve böbrek fonksiyon bozukluğu olan hastalar ile diabetik akut komplikasyon nedeni ile başvuran hastalar (hipoglisemi, diyabetik ketoasidoz, laktik asidoz, hiperosmolar nonketotik koma) çalışmaya alınmadı.

\section{İstatistiksel Analiz}

İstatistiksel analizler IBM SPSS for Windows Version22.0 paket programında yapıldı. Sayısal değişkenler ortalama \pm standart sapma ve median [min-maks] ile kategorik değişkenler ise sayı ve yüzde ile özetlendi. Gruplar sayısal değişkenler bakımından karşılaştırılmadan önce parametrik test varsayımları (normallik ve varyansların homojenliği) kontrol edildi. İki bağımlı grup arasında sayısal değişkenler bakımından farklılık olup olmadığı parametrik test varsayımlarının sağlanması durumunda bağımlı gruplarda paired samples test ile araştırıldı. Parametrik test varsayımlarının sağlanmaması durumunda ise Wilcoxon sign testi kullanıldı. Gruplar arasında kategorik değişkenler bakımından farklılık olup olmadığ 1 Ki-Kare testi ile incelendi. Anlamlılık düzeyi $p<0,05$ olarak alındı. 


\section{BULGULAR}

Çalışmaya alınan hastaların 58'i kadın 42'si erkekti. Yaş dağılımlarına bakıldığında kadınların \%47, erkeklerin ise \%30 oranında 41-65 yaş aralığında olduğu tespit edildi (Tablo 1). Ortalama diyabet süresi 3 yil 3 ay olarak bulundu.

\begin{tabular}{|llc|}
\hline \multicolumn{2}{|l|}{$\begin{array}{l}\text { Tablo 1. Çalışmaya alınan hastaların yaşa ve cinsiyete göre } \\
\text { dağılımlarını gösteren veriler }\end{array}$} & Sayı \\
\hline Yaş & Cinsiyet & 1 \\
\hline \multirow{3}{*}{40 yaş ve altı } & Kadın & 2 \\
& Erkek & 3 \\
& Toplam & 47 \\
41 - 65 yaş arası & Kadın & Erkek \\
& Toplam & 30 \\
& Kadın & 77 \\
66 yaş ve üstü & Erkek & 10 \\
& Toplam & 10 \\
& Kadın & 20 \\
Toplam & Erkek & 58 \\
& Toplam & 42 \\
\hline
\end{tabular}

Hastalarda görülen mikrovasküler komplikasyonlardan en fazla nefropati $\% 79$, makrovasküler komplikasyonlardan en fazla hipertansiyon \%58 oranında saptandı. Hastalarda makrovasküler komplikasyonlardan SVO ve PAH yoktu ve 73 hasta da (\%73) hiperlipidemi eşlik etmekteydi (Şekil 1).

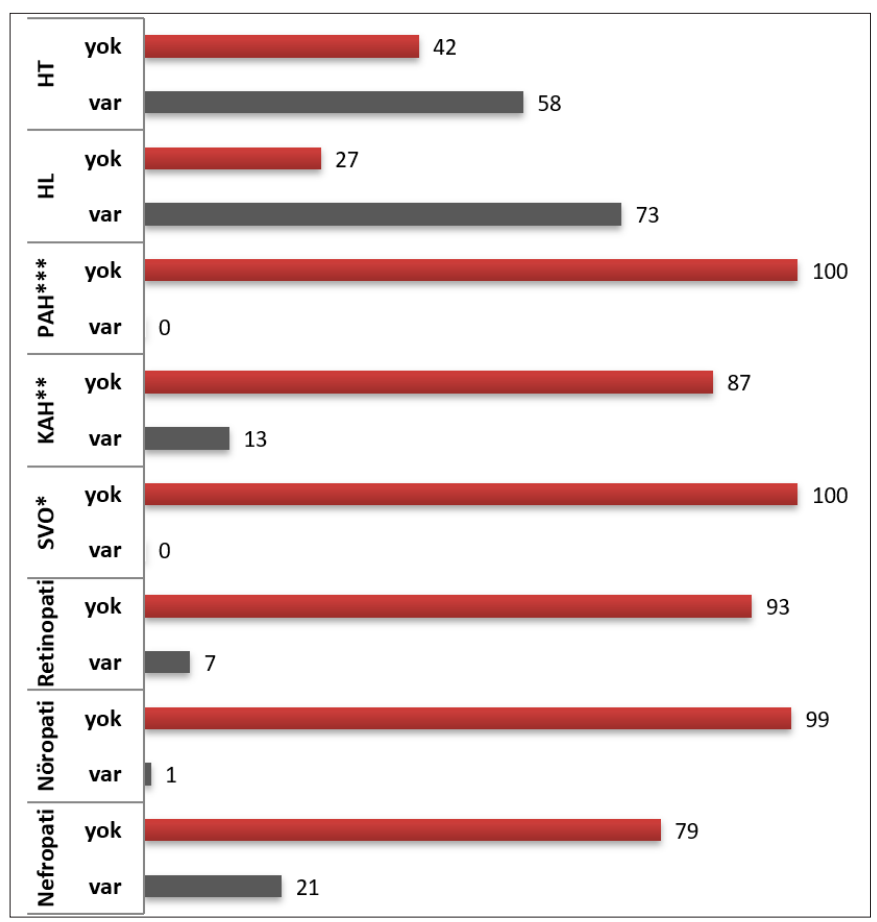

Sekil 1. Calışmaya alınan hastaların mikrovasküler ve makrovasküler komplikasyonlara göre gruplandırılması

SVO*: Serebrovasküler olay, PAH**: Periferik Arter Hastalığı, $\mathrm{KAH}^{* * *}$ : Koroner Arter Hastalığı
Hastaların ilk çalışmaya alındığı döneminde ortalama HbA1c \%9,41 $\pm 2,04$ iken takip eden dönemde kontrol muayenesi döneminde $\mathrm{HbAlc} \% 7,42 \pm 1,48$ olarak bulundu. Her iki grup arasında istatistiksel olarak anlamlı farklılık mevcuttu $(\mathrm{p}<0,001)$. HbA1c değerinin ortalama \%9,4 olduğu ilk başvuru döneminde ortalama AKŞ 197 $\mathrm{mg} / \mathrm{dl}, \mathrm{HbAlc}$ değerinin ortalama \%7,4 olduğu kontrol muayenesi dönemindeki ortalama değerleri AKŞ $152 \mathrm{mg}$ /dl olarak saptandı ve $\mathrm{p}<0,001$ olarak görüldü. İlk başvuruda ortalama TKŞ $330 \mathrm{mg} / \mathrm{dl}$, kontrol muayenesinde ortalama TKŞ $152 \mathrm{mg} / \mathrm{dl}$ olarak saptand, her iki grup arasinda anlamlı farklılık mevcuttu $(\mathrm{p}<0,001)$. HbAlc \%9,4 iken ortalama MPV 10,12 fL, HbA1c \%7,4 olduğu dönemdeki ortalama MPV 10,10 fL olarak saptand, her iki grup arasinda anlamlı farklılık bulunamad. HbAlc \%9,4 iken ortalama RDW \%13,5, HbA1c \%7,4 olduğu dönemde ise RDW \%13,8 olarak saptandı ve her iki grup arasında anlamlı farklılık mevcuttu (p:0,009). Hastaların lipid paneli ve diğer değerlerinin ortalamaları ile $\mathrm{p}$ değerleri Tablo 2'de gösterilmiştir.

Tablo 2. Hastaların ilk başvuru ile kontrol muayeneleri sırasında HBA1C, MPV ve RDW ile bazı laboratuvar değerlerinin karşılaştırılması

\begin{tabular}{|lccc|}
\hline Parametreler & İlk başvuru & $\begin{array}{c}\text { Kontrol } \\
\text { muayenesi }\end{array}$ & P değeri \\
\hline AKŞ (mg/dL) & $197,58 \pm 74,75$ & $152,52 \pm 54,62$ & $\mathrm{P}<0,001$ \\
TKŞ (mg/dL) & $330,63 \pm 116,73$ & $245,61 \pm 80,19$ & $\mathrm{P}<0,001$ \\
HbA1C $(\%)$ & $9,41 \pm 2,04$ & $7,42 \pm 1,48$ & $\mathrm{P}<0,001$ \\
Trigliserit $(\mathrm{mg} / \mathrm{dL})$ & $183,51 \pm 127,93$ & $170,29 \pm 102,01$ & 0,298 \\
T.kol $(\mathrm{mg} / \mathrm{dL})$ & $200,04 \pm 47,16$ & $193,59 \pm 40,51$ & 0,148 \\
LDL $(\mathrm{mg} / \mathrm{dL})$ & $121,25 \pm 36,97$ & $114,36 \pm 33,93$ & 0,034 \\
HDL $(\mathrm{mg} / \mathrm{dL})$ & $45,45 \pm 11,81$ & $45,96 \pm 11,82$ & 0,571 \\
PLT $\left(/ \mathrm{mm}{ }^{3} \times 10^{3}\right)$ & $258,27 \pm 68,61$ & $263,15 \pm 70,01$ & 0,200 \\
MPV (fL) & $10,13 \pm 1,56$ & $10,10 \pm 1,64$ & 0,902 \\
RDW $(\%)$ & $13,56 \pm 1,09$ & $13,86 \pm 1,43$ & 0,009 \\
\hline
\end{tabular}

\section{TARTIŞMA}

Bu çalışmada MPV ve RDW'nin DM hastalarındaki klinik aktivite düzeyleri ile olan ilişkisi araştırıldı. DM tanısı olan hastaların çalıșmaya alındıkları ilk dönemleri ile kontrole geldikleri dönemlerinde $\mathrm{HbA1c}$, AKŞ, TKŞ, RDW anlamlı olarak farklı izlendi. HbAlc düşüşü görülürken RDW değerinde artıș olduğu görüldü. MPV ile ilgili anlamlılık bulunamadı. Literatürden farklı olarak HbA1c düșerken RDW gibi bir inflamatuvar belirteçte artıs olması bize takip süresinin kısa olmasından, lipid profilinde yeterince gerileme olmamasından kaynaklı olduğunu düșündürmektedir. Literatürde birçok çalıșmada RDW ve MPV değerlerinin lipid profilinden etkilendiği bildirilmiștir.

Diabetes mellitusun kendisinin başlattığı VLDL'de artış, artmış aterojenik küçük yoğun LDL partikülleri, azalmış HDL, artmış lipoprotein oksidasyonu, azalmış glikozilasyonu, azalmış lipoprotein lipaz aktivitesi şeklindeki lipid 
anormallikleri, platelet agregasyon ve adhezyonunda artma, endotel hücre disfonksiyonu ve artmış prokoagulan durum; örneğin pıhtılaşma faktörleri ve fibrinojende artma, antitrombin III, protein C ve S'te azalma, fibrinolitik aktivitede azalma, aterosklerozu hızlandırmaktadır. Literatürde bir çok çalışmada lipid düzeyi ile RDW ve MPV arasında ilişki olduğu gösterilmiş. Zhang Minzhou ve arkadaşlarının yaptığı çalışmada LDL ve trigliserit düzeylerindeki azalma ile MCV, MPV ve PDW değerlerinin de anlamlı olarak azaldığı gösterilmiş (13). Karakilcik ve arkadaşlarının yaptığ çalışmada egzersiz ve egzersiz artı vitamin $\mathrm{C}$ ile $\mathrm{HDL}$ düzeylerinde artış, LDL düzeyinde azalma saptanmış lipid proflindeki bu değişim ile RDW, MPV, trombosit sayısında saptanan anlamlı düşüş arasında ilişki olduğu gösterilmiş (14).

Biz de çalışmamızda HbA1c ve hiperlipideminin MPV ve RDW üzerindeki etkisini görmeyi amaçladık. Çalışmamızda MPV değerinin literatürle uyumlu olarak ilk başvuru anında artmış, kontrol muayenesi döneminde azalmış olduğunu bulduk. Fakat bu düşüş istatistiksel olarak anlamlı değildi. HbA1c'de düşüş sağlandıktan sonraki takip süresinin, MPV üzerindeki etkiyi görecek kadar yeterli olmaması, hipertrigliserideminin devam etmesi ve HDL düzeyinde anlamlı artış olmaması nedeni ile MPV değerinde düşüş olmakla beraber istatistiksel olarak anlamlı düşüş görülmedi. Bu durumda takip süresinin uzatılması, trigliserit düzeyinde anlamlı düşme ve HDL de anlamlı yükselme sağlandıktan sonra MPV değerindeki değişimin değerlendirilmesi ile daha doğru bilgiler vereceği düşünülmüştür.

Lippi ve arkadaşlarının yaptığı çalışmada özellikle kadınlarda RDW'nin daha yüksek olduğu ve hipertrigliseridemi ile RDW arasında pozitif ilişki olduğu saptanmıştır (15). Çalışmamızda kadın ve erkeklerde ayrı ayrı bakıldığında kadınlarda RDW ortalama değerinin daha yüksek olduğunu gördük. Çalışmamızda kadın hasta sayımız erkek hasta sayısına göre daha yüksekti. Çalışmaya alınan hastaların takip süresinin kısa olması nedeni ile RDW değeri normal aralıkta saptanmış olabilir. Hiperglisemi, hiperinsülinemi ve hiperlipidemi MPV'yi, RDW'den daha fazla etkiliyor olabilir. Çalışmaya alınan hastaların \%58'inin kadın olması ve hipertrigliserideminin devam etmesi, HDL'de anlamlı yükselme olmaması nedeni ile RDW'de artış saptanmış olabilir. Bu konuda vaka sayısı arttırılarak daha uzun süreli takip ile ileri çalışmaların yapılması gerekmektedir.

$\mathrm{Bu}$ sonuç bize RDW düzeyindeki artışın, primer $\mathrm{Hb}$ glikolizasyonuna bağlı olmadığını düşündürmüştür. Lipid metabolizmasındaki değişim ve belki de kan şekeri yüksekliğinin yapmış olduğu inflamatuvar sürecin gerilemesi Hb'in glikolizasyonundan daha uzun sürüyor olabilir. Bu nedenle RDW düzeyleri uzun süre yüksek seyredebilir.

\section{SONUÇ}

MPV ve RDW ucuz ve pratik bakılabilen parametreler olmasına karşın, DM komplikasyonlarının erken dönemde belirlenmesini sağlayan çok önemli biyomarkerlardır. Komplikasyonların erken dönemde tespit edilmesi ile hastane yatıs süresinde, mortalite ve morbidite oranlarında azalma sağlanabilir. Bizim çalışmamızın kısıtlılıkları olarak vaka sayısının az olması ve takip süresinin kısa olmasını söyleyebiliriz. Bu nedenle HbA1c'deki değişimin ve hiperlipideminin, MPV ve RDW üzerine olan etkisini görmek için daha çok vaka sayısı ile daha uzun süreli takipler yapmak gerekmektedir.

\section{ETIKK BEYANLAR}

Etik Kurul Onayı: Çalışma Ankara Numune Eğitim ve Araştırma Hastanesi (ANEAH) Bilimsel Araştırmalar Değerlendirme Komisyonu (Etik Kurulu) tarafindan onaylanmıştır (Tarih: 04/06/2014, Karar No: 2014-835).

Aydınlatılmış Onam: Çalışma retrospektif olarak dizayn edildiği için hastalardan aydınlatılmış onam alınmamıştir.

Hakem Değerlendirme Süreci: Harici çift kör hakem değerlendirmesi.

Çıkar Çatışması Durumu: Yazarlar bu çalışmada herhangi bir çıkara dayalı ilişki olmadığını beyan etmişlerdir.

Finansal Destek: Yazarlar bu çalışmada finansal destek almadıklarını beyan etmişlerdir.

Yazar Katkıları: Yazarların tümü; makalenin tasarımına, yürütülmesine, analizine katıldığını ve son sürümünü onayladıklarını beyan etmişlerdir.

\section{KAYNAKLAR}

1. Aguiree F, Brown A, Cho NH, et al. IDF Diabetes Atlas. 2013

2. Satman İ, Alagöl F, Ömer B ve ark. Türkiye Diyabet, Hipertansiyon, Obezite ve Endokrinolojik Hastalıklar Prevalans Çalışması-II (TURDEP-II Çalışması). 2010

3. Hsueh WA. In diabetes,treat hidden heart disease. Cleve Clin J Med 2000; 67: 807-13.

4. Beckman JA, Creager MA, Libby P: Diabetes and atherosclerosis: epidemiology, pathophysiology, and management. JAMA 2002; 287: $2570-81$.

5. Marso SP. Optimizing the diabetic formulary: Beyond aspirin and insulin. J Am Coll Cardiol 2002; 40: 652-61.

6. Executive Summary of The Third Report of The National Cholesterol Education Program (NCEP) Expert Panel on Detection, Evaluation, And Treatment of High Blood Cholesterol In Adults (Adult Treatment Panel III). JAMA 2001; 285: 2486-97.

7. Esser N, Legrand-Poels S, Piette J, Scheen AJ, Paquot N. Inflammation as a link between obesity, metabolic syndrome and type 2 diabetes. Diabetes Res Clin Pract 2014; 105: 141-50.

8. Shoelson SE, Lee J, Goldfine AB. Inflammation and insulin resistance. Journal of Clinical Investigation 2006; 116: 1793.

9. Dandona P, Aljada A and Bandyopadhyay A, Inflammation: the link between insulin resistance, obesity and diabetes. Trends in Immunology 2004; 25: 4-7. 
10. Pierce CN, Larson DF. Inflammatory cytokine inhibition of erythropoiesis in patients implanted with a mechanical circulatory assistdevice. Perfusion 2005; 20: 83-90.

11. Weiss G, Goodnough LT. Anemia of chronicdisease. N Engl J Med 2005; 352: 1011-23.

12. Braunwald E, Fauci AS, Kasper DL, Hauser SL, Longo DL, Jameson JL. Harrison İç Hastalıkları Prensipleri Nobel Tip Kitabevleri 15. Bask1 2004: 1382-86, 2109-43.

13.Zhang MZ, Li S, Zou X, et al. Effect of Tongguan capsule on blood lipid and coagulation in patients with CHD after PCI. J Guangzhou Univ Tradit Chin Med 2004; 21: 93-7.

14. Karakilcik AZ, Halat R, Zerin M, Nazligul Y. Effect of vitamin C and exercise on lipid profile, platelet and erythrocyte indices in young soccerplayers. J Sport Med Physical Fitness 2014; 54: 66571.

15.Lippi G, Sanchis-Gomar F, Danese E, Montagnana M. Associated of red blood cell distribution width with plasma lipids in a general population of unselected outpatients. Kardiol Pol 2013; 71: 931-6. 